\title{
Chapter 4 \\ The Role of Managed Forest Ecosystem: An Inventory Approach
}

\author{
Anna Barbati and Piermaria Corona
}

\begin{abstract}
The use of statistical sampling coupled with periodic re-measurements in permanent sample units provides the basis for accurate measuring changes in forest extent and conditions, and constructing reliable models to estimate trends. This chapter explores this topic in order to understand how to integrate land use and forest inventory approaches so to estimate $\mathrm{CO}_{2}$ emissions and removals in managed forest ecosystems. The approach adopted by the Italian National Registry of carbon sinks, targeted to report the activities elected by Italy under the articles 3.3 and 3.4 of the Kyoto Protocol, is based upon the integration of a robust land use inventory, driven by ortho corrected airborne images, and field data from the permanent plots of the national forest inventory. On the whole, the amount of forest land remaining forest in the period 1990-2008 is estimated to exceed 9,000,000 ha; since 1990, over 350,000 ha of croplands and grasslands have been converted to forest, while nearly 127,000 ha have been deforested. The annual change in aboveground living tree biomass in forest land is estimated as high as $+14.7 \mathrm{Mt}$, with an uncertainty (95\% confidence interval) of $\pm 2.8 \mathrm{Mt}$, which corresponds to an annual carbon gain estimated between $1.35 \mathrm{t} \mathrm{Cha}^{-1} \mathrm{y}^{-1}$ and $1.45 \mathrm{t} \mathrm{C} \mathrm{ha}^{-1} \mathrm{y}^{-1}$.
\end{abstract}

\subsection{Introduction}

Sample surveys are recognized as key tools to estimate changes in land use or in carbon stocks by the Intergovernmental Panel on Climate Change (IPCC) Good Practice Guidance for Land Use, Land Use Change and Forestry

\footnotetext{
A. Barbati $(\triangle)$

Department for Innovation in Biological, Agro-Food and Forest Systems, University of Tuscia, Viterbo, Italy

e-mail: barbati.sisfor@unitus.it

P. Corona

Forestry Research Centre, Consiglio per la ricerca e la sperimentazione in agricoltura, Arezzo, Italy
} 